\title{
A China na ordem ambiental internacional das mudanças climáticas
}

\author{
HELENA MARGARIDO MOREIRA I \\ e WAGNER COSTA RIBEIRO ${ }^{I I}$
}

\section{Introdução}

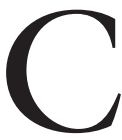

OMO ATOR global, a China hoje pode ser considerada um país-chave na política climática internacional. Além disso, é também o maior emissor de gases de efeito estufa (GEE) do mundo desde 2007, quando ultrapassou os Estados Unidos da América. De acordo com Heggelund, Andresen e Buan (2010), outra razão que faz da China um ator essencial nas negociações climáticas é o seu status e influência no G77, grupo que congrega os países em desenvolvimento para aumentar sua capacidade de negociação no sistema ONU. Os autores afirmam que a atuação chinesa junto ao G77 lhe dá proeminência nas negociações climáticas, pois o país é uma liderança no grupo. Além disso, é um participante ativo desde a elaboração da Convenção-Quadro das Nações Unidas sobre Mudanças Climáticas (CQNUMC), em 1992, passando pelas negociações para o estabelecimento do Protocolo de Kyoto (PK), definido em 1997, e conquista cada vez mais importância nas rodadas da ordem ambiental internacional sobre as mudanças climáticas ${ }^{1}$ (Ribeiro, 2005).

A postura chinesa nas negociações internacionais sobre mudanças climáticas, apesar de muito participativa e fundamental para o encaminhamento das decisões globais sobre o tema, é definida em termos do interesse desenvolvimentista do Estado chinês. O objetivo deste artigo é analisar a participação da China nas rodadas da ordem ambiental internacional das mudanças climáticas partindo do argumento de que a política externa chinesa para o tema é subordinada aos interesses domésticos do país, que estão focados na promoção de seu desenvolvimento econômico.

Para isso, definimos como objeto de análise duas Conferências das Partes (COP) da CQNUMC, a Conferência de Copenhague, em 2009, e a Conferência de Doha, em 2012, para analisar como a postura chinesa respondeu aos interesses econômicos do país, objetivo deste artigo. A escolha dessas duas conferências deve-se ao fato de serem um marco na construção da ordem ambiental internacional das mudanças climáticas. A Conferência de Copenhague por ter marcado uma mudança nos posicionamentos dos países e ter sido cercada de 
grandes expectativas para a formação de um acordo global; a de Doha, ${ }^{2}$ por marcar o fim do primeiro mandato do Protocolo de Kyoto e início de um período que deve ser finalizado com a assinatura de um novo acordo.

Em um primeiro momento, retomaremos a participação chinesa em dois episódios fundamentais da política climática internacional: a elaboração da Convenção do Clima, durante a Conferência das Nações Unidas para o Meio Ambiente e Desenvolvimento (CNUMAD), em 1992 (também chamada de Rio 92), e a adoção do PK, destacando sua participação conjunta com o G77. Em seguida, analisaremos o desenvolvimentismo chinês com base na análise de documentos, como os planos quinquenais, a Política Nacional para as Mudanças Climáticas, e também na definição dos atores domésticos responsáveis pela política climática e econômica chinesas. Analisaremos, na última parte do artigo, a participação do país nas duas Conferências citadas identificando nestas a tentativa de garantir, prioritariamente, seus objetivos de desenvolvimento econômico. Este trabalho foi baseada na análise de documentos oficiais, disponíveis na página da CQUNMC, relativos às decisões tomadas e dos discursos oficiais proferidos pelas autoridades chinesas e representantes do G77/China. Além disso, a presença da autora durante sua participação ${ }^{3}$ como observadora na $18^{\text {a }} \mathrm{COP}$, realizada em Doha, em 2012, permitiu levantar informações in loco, recolhidas em coletivas de imprensa e pelo acompanhamento das negociações.

\section{O despertar: a participação chinesa na formação da ordem ambiental internacional das mudanças climáticas}

As mudanças climáticas tornaram-se um assunto de política pública e política internacional em meados dos anos 1980, o que impulsionou a criação do IPCC. ${ }^{4}$ As negociações sobre mudanças climáticas que resultaram na CQNUMC (aberta para assinaturas em 1992) e, depois, no PK (em vigor desde 2005), tiveram início nas reuniões preparatórias da Rio 92. A Convenção-Quadro estabeleceu a COP (Conferência das Partes) como órgão decisório para a tomada de ação e a discussão, pelos países-membro, das diversas questões que envolvem as mudanças climáticas e a implementação da Convenção, que, desde 1995, ocorrem anualmente. Também definiu que cabe à Secretaria Geral da CQNUMC implementar as decisões e colaborar para que os países-membro possam internalizar o que foi definido nas COP.

Além disso, dividiu os Estados signatários em dois grupos: Partes Anexo I, que congrega a União Europeia mais os membros da OCDE (Organização para a Cooperação e Desenvolvimento Econômico) e os países industrializados ex-comunistas em transição para uma economia de mercado que devem responder pelas ações de mitigação das mudanças climáticas, com metas de redução das emissões de gases de efeito estufa, e Partes Não Anexo I, que reúne todos os demais países-membros (em desenvolvimento e menos desenvolvidos) que, por não terem responsabilidade histórica sobre o aumento das emissões de GEE, ficam obrigados a elaborarem inventários nacionais de emissões (Viola, 2003). 
Essa divisão segue o princípio das "responsabilidades comuns, porém diferenciadas" (CBDR, sigla em inglês), que é um dos alicerces da ordem ambiental internacional das mudanças climáticas. Segundo Serra (2010), a responsabilidade é comum porque quase toda atividade humana gera, em todos os países, emissões de GEE, mas ela também é diferenciada porque os países mais industrializados são mais responsáveis pelas causas do aquecimento global, já que emitiram mais GEE ao longo da história. De acordo com esse princípio, esses devem reduzir suas emissões antes que os demais.

O PK avançou ao estabelecer metas de redução das emissões de GEE na atmosfera a serem cumpridas pelos países Anexo I, entre 2008 e 2012. Portanto, o Protocolo se configurou como o acordo-marco para formalizar os objetivos das políticas de mitigação das emissões de GEE em nível internacional.

A China iniciou sua participação ativa na formação da ordem ambiental internacional das mudanças climáticas desde as negociações para a elaboração da CQNUMC. Essa participação pode ser marcada por dois momentos: a consecução da CQNUMC e do PK. Considerando esses dois marcos, Bjørkum (2005) divide a participação do país nas negociações climáticas em três etapas, de 1988 a 1992, de 1992 a 1997, e a partir de 1998.

A primeira fase engloba a participação chinesa durante a Rio 92. A partir de 1988, com a entrada definitiva das mudanças climáticas na agenda internacional, impulsionada pela criação do IPCC, a China iniciou a sua política climática nacional, o que levou à criação do National Climate Change Coordination Group (NCCCG), formado por quatro outras instituições: Comissão Estatal de Ciência e Tecnologia (SSTC, sigla em inglês), Agência Nacional de Proteção Ambiental (Nepa, sigla em inglês), Administração Meteorológica Estatal (SMA, sigla em inglês) e o Ministério das Relações Exteriores (Mofa, sigla em inglês).

$\mathrm{Na}$ fase de negociação e elaboração da Convenção do Clima duas questões eram essenciais para a China: primeiro, se a convenção teria metas específicas de redução das emissões de GEE e, segundo, até que ponto os países em desenvolvimento deveriam participar. Sobre a posição chinesa nessa fase, Bjørkum (2005, p.27, tradução livre dos autores) afirma o seguinte:

Durante a fase de negociação, a delegação chinesa se opôs fortemente à ideia de metas e prazos, e apoiou uma convenção-quadro geral sem responsabilidades específicas para as Partes. A China também foi bem-sucedida em estabelecer uma frente unificada de países em desenvolvimento de forma a resistir às demandas dos países industrializados por compromissos por parte dos países em desenvolvimento. Desde o início das negociações climáticas, a China ganhou a reputação de "linha-dura".

Assim como todos os países do G77, ${ }^{5}$ os elementos centrais da posição chinesa nessa fase inicial de negociação fiavam-se nos seguintes argumentos: incertezas científicas sobre as mudanças climáticas; defesa da soberania nacional e do direito ao desenvolvimento; responsabilidade histórica dos países indus- 
trializados; e transferência de fundos e tecnologias para os países em desenvolvimento (Bjørkum, 2005). Fica claro que o G77 exerceu grande influência na estruturação do que veio a ser a Convenção do Clima, especialmente no que diz respeito ao princípio $\mathrm{CBDR}$ e à manutenção do sistema climático com base na equidade. Durante o processo negociador da Convenção, esse princípio foi uma das bases para a elaboração do documento e para a estruturação da ordem ambiental internacional das mudanças climáticas.

Dado que o objetivo da Convenção do Clima não dispõe sobre os meios de se alcançar a estabilização das concentrações de GEE era necessário que se estabelecesse um processo negociador para a elaboração de um protocolo adicional juridicamente vinculante. Tal processo foi iniciado na primeira COP, realizada em Berlim, em 1995, quando os países decidiram estabelecer um protocolo multilateral de cumprimento legal obrigatório para seus signatários para fixar metas e procedimentos de mitigação das emissões de GEE. Assim, as Partes da Convenção adotaram o Mandato de Berlim, que definiu um prazo de dois anos para que tal protocolo fosse elaborado, processo esse que culminou com o texto do PK, que seria aprovado e aberto a assinaturas em 1997 (Marcovitch, 2006).

No período entre a CQNUMC (assinada pela China em 1992 e ratificada em 1994) e a assinatura do PK, a política externa chinesa para as mudanças climáticas entra em sua segunda fase. Segundo Bjørkum (2005), durante as negociações da COP 1 a China destacou que a implementação dos compromissos já existentes deveria ser a principal preocupação da conferência e, assim, mostrava seu ceticismo com a proposta de um protocolo, pois o país não estava interessado em negociá-lo enquanto as Partes Anexo I não tivessem implementado seus compromissos de acordo com a Convenção do Clima.

A virada nas negociações ocorreu quando um grupo de países, liderados pela China, apoiou uma declaração dos pequenos Estados-ilha afirmando que os compromissos das Partes Anexo I perante a Convenção eram inadequados para enfrentar os riscos das mudanças climáticas, adotando em consequência o Mandato de Berlim para que os países desenvolvidos assumissem ações concretas. A contrapartida chinesa para o apoio aos Estados-ilha foi uma recusa definitiva em aceitar quaisquer novos compromissos para os países em desenvolvimento nas rodadas seguintes de negociação do Mandato de Berlim (Bjørkum, 2005).

Quando tiveram início as negociações da COP 3 , que adotou o PK, a posição inicial da China era de que "os países desenvolvidos deveriam reduzir suas emissões de $\mathrm{CO}_{2}, \mathrm{CH}_{4}$ e $\mathrm{N}_{2} \mathrm{O}$ aos níveis de 1990 até o ano 2000. E então reduzir $7,5 \%$ até $2005,15 \%$ até 2010 e $20 \%$ até 2020 , somando tudo a uma redução total de 35\% até 2020" (Bjørkum, 2005, p.29).

Com uma posição mais unificada do que a dos países desenvolvidos, o G77/ China se mostrou bastante influente nas negociações que resultaram no PK e em sua implementação. A China conseguiu garantir, ainda, a retirada de um artigo sobre compromissos voluntários para países em desenvolvimento (Bjørkum, 2005). 
Com a assinatura do PK, a política chinesa para as mudanças climáticas entra em sua terceira fase. Nessa etapa, os principais tópicos da diplomacia chinesa eram como assegurar que compromissos para os países em desenvolvimento fossem evitados e como atuar diante dos mecanismos criados pelo Protocolo, especialmente o Mecanismo de Desenvolvimento Limpo (MDL), ${ }^{6}$ além de evitar a discussão sobre compromissos voluntários para países em desenvolvimento.

De acordo com a delegação chinesa, compromissos voluntários não promoveriam a Convenção-Quadro e eram apenas uma forma de algumas Partes evitarem os compromissos existentes. A ideia de compromissos voluntários para países em desenvolvimento também levantou a preocupação de que os países em desenvolvimento arriscariam perder assistência financeira e transferência de tecnologia como estipulado na Convenção, se eles acordassem em assumir compromissos voluntários. Além disso, a China expressou sua preocupação de que os compromissos voluntários criassem uma nova categoria de Partes sob a Convenção e destruísse a unidade do "G77 e China". (Bjørkum, 2005, p.30, tradução livre dos autores)

As negociações para a implementação do $\mathrm{PK}$ seguiram nos anos posteriores e na COP 5, realizada em Bonn em 1999, a China diminuiu um pouco o tom nas negociações, explicando porque não aceitava discutir sobre compromissos futuros: "é impossível para o governo chinês comprometer-se a qualquer obrigação de redução de GEE antes que a China alcance os níveis de um país medianamente desenvolvido", afirmou Liu Jiang, chefe da delegação chinesa, citado por Bjørkum (2005, p.30). Ainda que o país já viesse crescendo significativamente há alguns anos, em termos econômicos, fica claro que o objetivo primeiro da China é garantir que a maioria de sua população deixe a linha de pobreza.

Outra mudança na postura chinesa foi com relação aos mecanismos flexibilizadores, apropriando-se mais das discussões após a COP 5 e participando das regras e procedimentos para a implementação prática de projetos de MDL, que passou a ser visto como um mecanismo win-win, beneficiando tanto países desenvolvidos quanto em desenvolvimento (Bjørkum, 2005). Em 2012, dos 4.772 projetos de MDL registrados pelo Conselho Executivo, 2.427 foram submetidos pela China, o que representa $50,86 \%$ do total de projetos de MDL registrados.?

Ainda que crescendo cada vez mais em termos de emissões de GEE, o que a colocaria em outra categoria em termos de compromisso de redução, a China continua se valendo do princípio que rege e estrutura a CQNUMC e documentos subsequentes para construir a sua posição nas negociações climáticas internacionais. A meta é garantir internacionalmente a ausência de metas de redução das suas emissões de GEE, uma forma de proteger seu interesse de desenvolvimento econômico, tido como prioridade doméstica para o governo chinês. No próximo item, veremos como está fundamentada a política desenvolvimentista chinesa e como esta influencia a política climática internacional do país. 


\section{O desenvolvimentismo chinês e a política climática internacional}

A China é um país de dimensões gigantescas, em termos territoriais e populacionais, com grande parte de sua população vivendo em situação de pobreza, mas com uma alta taxa de crescimento econômico e, consequentemente, taxas de emissão de GEE cada vez maiores. A busca de recursos naturais que garantam seu firme desenvolvimento econômico deixa o país em uma posição de importante ator global, especialmente quando se discutem temas como energia, mudanças climáticas, desenvolvimento econômico e segurança internacional.

Os desafios chineses são grandes, já que apresentam a maior população mundial, que ainda não atingiu os indicadores sociais de outros países mais ricos, associada à complexa condição climática do país. Esses vetores fazem das mudanças climáticas um tópico de grande preocupação para o governo chinês, mas ainda subordinado às suas necessidades de desenvolvimento. A China é o Estado no mundo que mais consome carvão e é o maior produtor de $\mathrm{CO}_{2}$, em termos absolutos. Segundo relatório da Agência Internacional de Energia Atômica (AIEA), até 2030, se medidas não forem adotadas, o montante de GEE produzido pela China será o dobro do montante total produzido por todos os países da OCDE, o que traz preocupações ao governo chinês com as potenciais influências das mudanças climáticas no desenvolvimento nacional (Hung; Tsai, 2012).

Quanto aos desafios que a China enfrenta como resultados das mudanças climáticas e os custos das mudanças climáticas, Hung e Tsai (2012, p.107, tradução livre dos autores) destacam o seguinte:

Os desafios incluem o derretimento das geleiras, especialmente no Tibete e Tianshan; perda na produção agrícola, que pode diminuir em até $10 \%$ até 2030 ; aumento do número de secas, tempestades, inundações e desastres naturais causados pelo clima extremo; elevação do nível do mar que vai afetar até 67 milhões de pessoas; e a exposição de outros $40 \%$ da população mundial à ameaça de um desastre natural. Tendo em conta que a China abriga uma enorme população de 1,3 bilhão de pessoas, recursos decrescentes, os problemas de poluição graves e uma economia em rápido crescimento - fatores típicos de um dilema de desenvolvimento -, o custo potencial da mudança climática para a China é extremamente alto.

Ainda que o objetivo central seja voltado aos interesses econômicos, a vulnerabilidade do país às mudanças climáticas tem chamado cada vez mais atenção do governo chinês, fazendo que as mudanças climáticas sejam cada vez mais percebidas como ameaça potencial aos interesses nacionais (Heggelund; Andresen; Buan, 2010). Fica claro que as mudanças climáticas podem ter consequências desastrosas para a China, degradando sua situação ambiental e impactando negativamente o seu crescimento econômico e até mesmo a estabilidade política. Além dos desafios domésticos, a China enfrenta crescente pressão internacional para assumir um papel mais ativo, devido ao aumento do poder do país e à con- 
sequente diminuição da percepção global da China como país em desenvolvimento (Hung; Tsai, 2012).

O envolvimento internacional da China tem relação direta com seu desenvolvimento econômico, pois a crescente interdependência econômica com o restante do mundo pode transformar a China em uma potência cooperativa e pacífica, com restrições ao uso da força (Oliveira, 1999). Niu (2013) afirma que o país busca se integrar de forma abrangente no sistema internacional, visando o status de grande potência ao mesmo tempo que defende uma estratégia que promova o desenvolvimento de todos os países e a segurança internacional. Nesse momento de aumento da influência externa da China, o país precisa garantir à comunidade internacional que sua ascensão é pacífica, pois ainda há desconfiança com relação aos objetivos chineses. Isso mostra que, nas palavras de Niu (2013, p.198), "as contribuições da China para os valores da sociedade internacional ainda não são claras; no longo prazo, o objetivo central da grande estratégia chinesa é de ser uma potência sustentável sem grandes guerras nem guerras frias duráveis".

$\mathrm{Na}$ análise desse autor, a ascensão da China não traz ameaças às grandes potências, pois o país é importante na cooperação para enfrentar os problemas globais. Segundo Niu (2013, p.202):

Discussões sobre a responsabilidade internacional da China refletem um desejo por traçar um guia para o futuro papel global do país. Com efeito, diante das profundas transformações contemporâneas, acadêmicos chineses são prudentes com relação à possibilidade de agendas secretas que busquem ocidentalizar a China, enganar a diplomacia chinesa ou pedir ao país que assuma custos da governança global que ultrapassem suas capacidades. Outros, porém, defendem uma perspectiva mais positiva. Para estes, o conceito de "parte responsável" deve ser entendido como um resultado lógico do ressurgimento da China no cenário internacional, contexto no qual a cooperação e assistência do país se tornam necessários no enfrentamento de problemas globais.

No tema das mudanças climáticas, a China mantém internacionalmente um papel ativo, participando de todas as negociações e buscando cooperação com outros países. Assim, o governo chinês evita a crescente pressão internacional para agir. Domesticamente, adota diversas medidas para reduzir os impactos negativos das mudanças climáticas ao mesmo tempo em que garante um desenvolvimento econômico firme (Hung; Tsai, 2012).

As mudanças climáticas são tratadas na China como assunto tanto relacionado a uma estratégia nacional para o desenvolvimento sustentável quanto como de colaboração internacional. Essa dualidade, segundo Qi, Ma e Zhang (2007), faz que a política climática chinesa varie frequentemente entre a ênfase doméstica e a internacional. No âmbito doméstico, destacaremos aqui a estrutura de governança para as mudanças climáticas dentro do governo chinês, identificando os principais atores e as políticas domésticas chinesas para tratar do tema. 
No âmbito internacional analisaremos, no próximo item, a atuação da China nas Conferências de Copenhague e Doha.

Heggelund, Andresen e Buan (2010) defendem que os interesses que guiam a política climática chinesa são ligados à política econômica do país e afirmam que ela acaba sendo definida por um jogo fechado entre ministros relevantes e outras agências. As prioridades oficiais da China são o desenvolvimento econômico, a redução da pobreza e a estabilidade social, o que levará também ao rápido crescimento econômico e à melhoria do padrão de vida.

Os principais órgãos que representam esses interesses econômicos são a National Development and Reform Comission (NDRC), a agência governamental macroeconômica de maior influência que vê as mudanças climáticas sob a perspectiva da economia e da energia, e o Ministério das Relações Exteriores, ator-chave no processo político internacional e considerado um linha-dura, pois sempre aponta a importância da economia, a soberania chinesa, o princípio CBDR e a necessidade de assistência financeira e tecnológica para os países em desenvolvimento. Órgãos como o Ministério de Proteção Ambiental e atores não estatais são mais proativos com relação às mudanças climáticas e às medidas necessárias para enfrentá-las, mas gozam de baixo prestígio interno (Heggelund; Andresen; Buan, 2010). Esse quadro mostra que a economia e a busca pelo desenvolvimento econômico são os principais determinantes da política climática chinesa.

A NDRC define a agenda e é o ator decisivo em questões domésticas. Como a NDRC tem a responsabilidade das políticas econômica e energética, ela define e estabelece os limites para a política climática. Como as mudanças climáticas estão sendo definidas principalmente como uma questão sensível da política externa, o MFA exerce grande influência nos níveis internacional e nacional. Até agora, esses atores representam os interesses nacionais chineses fundamentais sobre a questão e têm sido a "coalizão vencedora" na elaboração da política climática chinesa. (Heggelund; Andresen; Buan, 2010, p.241, tradução livre dos autores)

Em entrevista concedida à autora como parte de um estágio de pesquisa realizado no Environmental Policy Research Centre da Universidade Livre de Berlim, em 2013, a Profa. Dra. Miranda Schreurs analisou os atores que desempenham papel fundamental na formulação da política climática chinesa, afirmando que o Politburo do Partido Comunista é quem determina se a China terá uma legislação climática e que a NDRC e outras organizações são os atores que definem que forma tomará essa política. Considerando que a China é um Estado centralizado e autoritário, tais órgãos sofrem pouca influência de outros atores como ONG, indústrias ou mesmo dos governos locais (províncias). Quanto à prioridade dada no âmbito doméstico ao tema das mudanças climáticas, Schreurs afirma o seguinte:

E a outra coisa que podemos dizer no caso da China é que eles ainda têm muitos problemas com a implementação da política climática, e é provavelmente por- 
que a mudança climática não é a prioridade para todos, não é sempre a prioridade no nível das províncias, e ainda também não é institucionalizada em todos os sentidos. Assim, você pode ter uma meta política e uma visão, mas se você não tem esse objetivo e visão institucionalizados, então ele pode ser difícil de se implementar. E assim, no caso da China, o que muitas vezes aprendemos é que os oficiais do Partido, a nível local, são promovidos pelo desempenho econômico, não pelo desempenho climático. Então, é claro que eles se concentram no desenvolvimento económico, por vezes, ao custo das mudanças climáticas, e talvez isso seja uma indicação de que a liderança por si só não é suficiente, você também precisa das instituições e capacidades certas (tradução livre dos autores). ${ }^{8}$

A maior parte das declarações oficiais acerca da política climática chinesa pode ser encontrada no National Coordination Group for Climate Change Strategies (NCG), ${ }^{9}$ do qual podemos extrair os princípios e estratégias do governo para o tema, como segue (Qi; Ma; Zhang, 2007):

1 - Atribuir grande importância para o tema de mudanças climáticas com base na estratégia de desenvolvimento sustentável: em 2006, a China adotou o desenvolvimento sustentável como a orientação chave e o objetivo estratégico para seu desenvolvimento social e econômico;

2 - Envolver-se ativamente nas atividades internacionais de mudanças climáticas baseada no princípio CBDR e considerando desenvolvimento econômico e redução da pobreza como prioridades;

3 - Promover a implementação de tratados internacionais e manter o interesse nacional;

4 - Melhorar a comunicação da contribuição da China para a mitigação das mudanças climáticas;

5 - Contribuir ativamente para a mitigação das mudanças climáticas com base nas políticas e medidas de desenvolvimento sustentável;

6 - Melhorar a conscientização pública; promover mudanças no estilo de vida e no consumo que resultem em redução das emissões de GEE;

7 - Fortalecer pesquisa científica em mudanças climáticas; aprimorar a capacidade nacional em participar das atividades relacionadas às mudanças climáticas globais.

Em seu Programa Nacional de Mudanças Climáticas, produzido pela NDRC em 2007, o governo chinês divulgou a situação do país com relação aos impactos e desafios das mudanças climáticas, os esforços internos que vêm sendo adotados, e linhas, princípios e políticas nacionais e internacionais da China para o tratamento do tema. Nesse documento, o governo reconhece as mudanças climáticas como um assunto de preocupação global e como um assunto que envolve meio ambiente e desenvolvimento, mas admite que é "em última análise um assunto de desenvolvimento" (NDRC, 2007, p.2).

Entre os esforços chineses para mitigar as mudanças climáticas, o Programa destaca os seguintes (NDRC, 2007, p.7-13): 
- Reestruturar a economia, promover o avanço tecnológico e melhorar a eficiência energética;

- Otimizar a matriz energética desenvolvendo energias renováveis e de baixo-carbono: o objetivo é diminuir a quota de combustíveis fósseis na matriz energética chinesa e, portanto, as emissões de GEE;

- Lançar uma campanha nacional de plantio de árvores e arborização e melhorar restauração e proteção ecológica;

- Controlar efetivamente o crescimento populacional por meio de planejamento familiar;

- Fortalecer leis e regulamentações, e políticas e medidas relevantes para o tratamento das mudanças climáticas, como por exemplo, o Plano de Conservação de Energia de Longo Prazo (2004);

- Melhorar ainda mais instituições e mecanismos, como o National Coordination Committee on Climate Change (NCCCC) responsável pela Comunicação Nacional da China para a Convenção do Clima;

- Atribuir grande importância para a pesquisa climática e construção de capacidade;

- Aprimorar educação, treinamento e conscientização pública em mudanças climáticas.

Fica claro que os esforços chineses para as mudanças climáticas, em termos domésticos, estão diretamente relacionados, e subordinados, às questões energéticas e de desenvolvimento e, em termos internacionais, fundamentados em uma liderança dos países desenvolvidos nas ações de mitigação das emissões de GEE, especialmente os Estados Unidos e os países da União Europeia, seguindo o princípio das "responsabilidades comuns, porém diferenciadas".

Bustelo (2007) critica o Programa, que para ele foca na primazia do crescimento econômico e na falta de metas para a redução da emissão de GEE, dado que o país claramente apresenta o desenvolvimento econômico e a redução da pobreza antes da luta contra as mudanças climáticas, já que considera que medidas muito rigorosas para cortar os GEE pode limitar seu potencial econômico. No entanto, o autor reconhece que um país com uma relativa baixa renda per capita (US\$ 1.740,00) e altos níveis de pobreza (de acordo com o Banco Mundial, em 2001, 16.6\% da população vivia com menos de um dólar por dia) ainda tem grandes necessidades econômicas e sociais. ${ }^{10}$

Em 2011, o governo chinês adotou o $12^{\circ}$ Plano Quinquenal, ${ }^{11}$ que estabelece as políticas para o período 2011-2015 e dá atenção considerável às questões energética e de mudanças climáticas. O plano apresenta metas para reduzir o consumo de energia fóssil e adotar um modelo de desenvolvimento chamado "economia de baixo-carbono" para reestruturar a economia chinesa. As metas principais do plano são: redução de $16 \%$ na intensidade energética (consumo de energia por unidade de PIB); aumentar a taxa de energia não fóssil para 11,4\% 
do uso total de energia; e uma redução de $17 \%$ na intensidade de carbono (emissões de carbono por unidade de PIB) (Lewis, 2011).

Um dos focos do documento é, portanto, a redução da intensidade energética e a promoção da eficiência energética. Isso significará também uma diminuição da taxa de crescimento do GDP para 7\% ao ano, menor do que as taxas atuais. Quanto à intensidade de carbono, o governo chinês propôs na Conferência de Copenhague (2009) uma redução de $40 \%$ a $45 \%$ na intensidade de carbono nacional até 2020 nos níveis de 2005 e, para atingir esse compromisso, o $12^{\circ}$ Plano Quinquenal determina uma meta de redução na intensidade de carbono de 17\% até 2015 nos níveis de 2010. No entanto, o alcance dessa meta dependerá da taxa de crescimento do PIB (Lewis, 2011).

Hung e Tsai (2012) relembram que o termo "economia de baixo-carbono" foi definido por Thomas e Boyle no artigo "At the energy crossroads: policies for a low-carbon economy", de 2001, que aponta que a mudança gradual para uma economia de baixo-carbono é a única resposta em direção ao desenvolvimento de energia renovável. De acordo com os autores, economia de baixo-carbono é um "modelo de desenvolvimento econômico que busca facilitar a transição de uma era de alto consumo de energia para uma de baixa consumo de energia melhorando a eficiência energética, promovendo a inovação de produtos de baixo-carbono e mantendo um balanço ambiental global" (Hung; Tsai, 2012 , p.114). Com esse novo modelo de desenvolvimento econômico, a China atrela as medidas climáticas e energéticas aos objetivos de desenvolvimento, com a preocupação de que os efeitos das mudanças climáticas afetem o crescimento econômico e a competitividade do país, mas mantém o interesse internacional no tema, buscando cooperação com os demais países:

Em suma, a nível interno, a China adere ao modelo de desenvolvimento da economia de baixo carbono e adota ativamente várias ações para reduzir os efeitos negativos das mudanças climáticas, equilibrando o objetivo de manter o desenvolvimento econômico estável. Internacionalmente, a China participa ativamente nas negociações sobre as mudanças climáticas e visa reforçar a cooperação com outros países. Ao manter o seu interesse sobre a questão das mudanças climáticas, não só a China pode evitar a pressão internacional cada vez maior de chamar o país a agir; como também pode evitar a contração da sua "auto-autonomia" na comunidade internacional. (Hung; Tsai, 2012, p.117, tradução livre dos autores)

A posição chinesa na ordem ambiental internacional das mudanças climáticas combina, portanto, desenvolvimento econômico e uma estratégia, lenta e gradual, de transição para uma economia de baixo-carbono. A questão aqui é: até que ponto essa matriz de referência está presente nas posições chinesas nas negociações climáticas internacionais? 


\section{A China como ator global nas negociações climáticas: Copenhague e Doha}

Diante da iminência do fim do mandato de Kyoto, foi preciso iniciar novo processo de discussão de medidas de mitigação e adaptação às mudanças climáticas. Por isso, nos últimos anos, temos acompanhado discussões sobre políticas de adaptação e mitigação que podem resultar, ou não, em um novo desenho que substitua o PK, na esfera internacional.

Para o novo período de compromisso está em discussão um maior envolvimento dos países em desenvolvimento para a redução das emissões de GEE, o que gerou um impasse. Nesse panorama, a China assume papel fundamental, dado que é o maior país em desenvolvimento, em termos populacionais, em ritmo de crescimento econômico e em emissões de GEE, o que gera grande pressão internacional para assumir metas de redução de suas emissões, ao mesmo tempo que, internamente, luta para tirar ainda grande parte de sua população de uma situação de pobreza.

Após a assinatura do PK as Conferências das Partes ocorreram anualmente de modo a determinar as formas de implementação do acordo e de seus mecanismos para que os países tivessem mais recursos disponíveis que os ajudassem a cumprir suas metas de redução das emissões de GEE. Os países em desenvolvimento, agrupados no G77/China, continuaram lutando para que os países desenvolvidos assumissem a liderança nas ações de mitigação das mudanças climáticas a fim de evitarem metas de redução das suas emissões. No ano 2005, em Montreal, tiveram início oficialmente as discussões internacionais do período pós-Kyoto, com a realização conjunta da $11^{\text {a }}$ Conferência das Partes da Convenção do Clima e do $1^{\circ}$ Encontro das Partes do Protocolo de Kyoto (COP 11/ MOP 1). Em 2007, durante a COP 13, em Bali, os países-membros presentes na Conferência aprovaram um "mapa do caminho" para dois anos de negociações para a redefinição da regulação internacional sobre o clima - o "Roteiro de Bali" - que culminaria na COP 15, em Copenhague, em 2009 (Brunnée, 2010).

Originalmente a COP 15 (Conferência de Copenhague) tinha como objetivo completar um novo acordo climático global para substituir o PK, e acabou tendo como resultado o Acordo de Copenhague, uma declaração de não cumprimento obrigatório que apenas reconhece a necessidade de estabelecer fortes medidas para segurar o aumento da temperatura global em até $2{ }^{\circ} \mathrm{C}$, conforme recomendava o Quarto Relatório do IPCC (Bailey, 2010).

Os únicos tipos de compromissos que o Acordo apresenta aos países Partes não incluídos no Anexo I, que inclui a China, é que eles deveriam implementar ações domésticas de mitigação, voluntárias, a serem submetidas ao Secretariado até 31 de janeiro de 2010, incluindo os relatórios de inventários nacionais (UNFCCC, 2009). 
A China comunicou seu plano de ações no documento Compilation of information on nationally appropriate mitigation actions to be implemented by Parties not included in Annex I to the Convention (UNFCCC, 2011, p.11), ${ }^{12}$ como segue:

A China comunicou que fará o possível para reduzir as suas emissões de $\mathrm{CO}_{2}$ por unidade do PIB em 40\%-45\% até 2020, em comparação com o nível de 2005. Ela também manifestou a intenção de aumentar a participação de combustíveis não fósseis no consumo de energia primária para cerca de $15 \%$ até 2020 e aumentar a cobertura florestal em 40 milhões de ha e o volume de estoque florestal em 1,3 bilhão de $\mathrm{m}^{3}$ até 2020 em comparação com os níveis de 2005 .

A China afirmou que as ações de mitigação domésticas autônomas acima mencionadas são de natureza voluntária e que serão implementadas de acordo com os princípios e disposições da Convenção, em especial o artigo 4, parágrafo $7 .{ }^{13}$ A Parte também afirmou que sua comunicação é feita de acordo com as disposições do artigo 12, parágrafos 1 (b) e $4^{14}$ e com os artigos 10, parágrafo $2(a)^{15}$ da Convenção. (tradução livre dos autores)

Em documento oficial que faz parte das posições defendidas pelo G77 no tema de mudanças climáticas, a China mostrou sua posição na Conferência de Copenhague, afirmando que as mudanças climáticas são um dos desafios mais sérios que a humanidade deve enfrentar no século XXI e que requer esforços conjuntos de toda a comunidade internacional. $\mathrm{O}$ documento afirma ainda que o país tem formulado e implementado o seu Programa Nacional de Mudanças Climáticas, adotando uma série de medidas internas para combater as mudanças climáticas (NDRC, 2009). ${ }^{16}$

De acordo com o documento China's Position on the Copenhagen Climate Change Conference (NDRC, 2009), os princípios sobre os quais se estabelece a posição chinesa no tratamento multilateral das mudanças climáticas são os seguintes:

l - A Convenção do Clima, o Protocolo de Kyoto e o Mapa do Caminho de Bali são as bases legais para a cooperação internacional para as mudanças climáticas. O Roteiro de Bali deve melhorar a implementação desses acordos;

2 - O princípio CBDR, que reafirma a demanda pela liderança dos países desenvolvidos em reduzir as emissões de GEE, em prover transferência de tecnologia e auxílio financeiro, enquanto os países em desenvolvimento irão, "em busca do desenvolvimento econômico e da erradicação da pobreza, adotar medidas proativas para se adaptarem e mitigarem as mudanças climáticas" (NDRC, 2009, p.2);

3 - O princípio do desenvolvimento sustentável, como a ferramenta adequada para que os países em desenvolvimento assegurem o seu direito ao desenvolvimento e busquem o desenvolvimento econômico integrado à redução da pobreza e à proteção do clima;

4 - Mitigação, Adaptação, Transferência de Tecnologia e Apoio Fnanceiro em pé de igualdade e como prioridades iguais para os países em desenvolvimento. 
A prioridade chinesa ao desenvolvimento pode ser atestada com o documento que trata das ações que cabem aos países em desenvolvimento, as $\mathrm{Na}$ tionally Appropriate Mitigation Actions (Nama). De acordo com a posição chinesa, essas "devem ser tomadas no contexto do desenvolvimento sustentável e alinhadas às legítimas necessidades prioritárias dos países em desenvolvimento e à erradicação da pobreza" (NDRC, 2009, p.4); ou seja, alinhadas às circunstâncias nacionais e às estratégias de desenvolvimento sustentável dos países em desenvolvimento, reafirmando assim a decisão chinesa de submeter a sua política climática às estratégias de desenvolvimento sustentável e aos objetivos de crescimento econômico.

Três anos após a Conferência de Copenhague, a COP 18/CMP 8 aconteceu em Doha, Catar. Em seus discursos, a China, o maior representante dos países em desenvolvimento e sempre falando em nome do G77/China, reafirmou os grandes desafios que o país enfrenta com relação às mudanças climáticas, especialmente no plano doméstico, e a necessidade de cooperação internacional para ajudar o país a superar esses desafios. A posição chinesa consiste basicamente em destacar a necessidade de transferência de tecnologia e apoio financeiro dos países desenvolvidos para os em desenvolvimento, e em defender o princípio CBDR como o princípio fundador da ordem ambiental internacional das mudanças climáticas. O Chefe da delegação chinesa durante a Conferência de Doha, Sr. Xie Zhenhua, afirmou que este princípio se aplica ao país devido ao fato de que toda a arena nacional deve ser considerada, dado que a China tem diferentes níveis de desenvolvimento entre suas províncias e, portanto, enquanto todas elas não alcançarem o nível de desenvolvimento desejado, o país como um todo deve ser considerado um país em desenvolvimento.

Em uma declaração feita pela China em nome de Brasil, Índia, África do Sul e China (Basic) na COP 18, o país afirma que as mudanças climáticas são um desafio transversal que enfraquece a habilidade dos países em desenvolvimento em alcançarem o desenvolvimento sustentável e, por causa disso, os países deveriam tomar ações concretas de acordo com os princípios da Convenção. A China resume a posição dos países em desenvolvimento como a seguir:

Enquanto o desenvolvimento sustentável e a erradicação da pobreza continuam a ser desafios urgentes e prioridades imperiosas de nossos países em desenvolvimento, nós já estamos tomando ações ambiciosas para reduzir as emissões e, como afirmado por muitos relatórios acadêmicos de organizações internacionais de renome, a nossa contribuição para a mitigação é muito maior do que aquelas dos países desenvolvidos, que têm maiores responsabilidades históricas e devem assumir a liderança no combate às mudanças climáticas. Exortamos as Partes países desenvolvidos a honrar os seus compromissos para reduzir suas emissões de forma ambiciosa e fornecer financiamento adequado, transferência de tecnologia e construção de capacitação, de modo a permitir que os países em desenvolvimento tomem medidas de combate às mudanças climáticas. (UNFCCC, 2012, p.l, tradução livre dos autores) 
Como podemos ver, a China mantém sua posição em defesa do direito ao desenvolvimento e ao objetivo de erradicação da pobreza. Ela também considera o desenvolvimento sustentável como o modelo que deve guiar os países em desenvolvimento a esses objetivos, destacando, contudo, a necessidade de assistência dos países desenvolvidos em oferecer financiamento, tecnologia e construção de capacidades. Fica evidente, pela declaração, que a China está preocupada com o futuro dos acordos climáticos e com a falta de medidas ousadas que deveriam ser tomadas pelos países desenvolvidos (UNFCCC, 2012).

Durante as discussões em Doha (2012), a China expressou preocupação especial com três principais tópicos de negociação, adaptação, financiamento e transferência de tecnologia, deixando claro que os países em desenvolvimento precisam de assistência dos países desenvolvidos para enfrentar os desafios das mudanças climáticas. A China também apela regularmente a um maior envolvimento dos países desenvolvidos em termos de metas de redução das emissões, mostrando insatisfação com o direcionamento das discussões.

Outro argumento importante defendido pela China durante a COP 18 foi a necessidade de considerar as circunstâncias nacionais de todos os países para as negociações de um novo acordo climático, significando que os países deveriam ter em mente dois aspectos da demanda por ações: as especificidades domésticas de cada país e suas prioridades de desenvolvimento, resumindo a característica mais importante da posição chinesa. Ao mesmo tempo, o governo chinês procurou mostrar que o país está comprometido com as ações climáticas domesticamente, expondo os objetivos do Programa Nacional de Mudanças Climáticas e do $12^{\circ}$ Plano Quinquenal, como os investimentos em eficiência energética para uma economia de baixo-carbono, afirmando que essa transformação pode melhorar a qualidade de vida da população chinesa.

Os resultados finais de Doha foram um conjunto de medidas que irão permitir o movimento das velhas negociações para forjar um novo acordo internacional, a ser desenhado até 2015 para entrar em vigor em 2020. Uma dessas medidas foi o acordo para estender o PK até 2020. No entanto, de acordo com Fiona Harvey, para que essas novas negociações sejam bem-sucedidas, "tanto os EUA quanto a China devem aceitar metas rígidas de corte de emissões, e encontrarem um jeito de fornecer ajuda financeira aos países pobres para ajuda-los a cortar emissões e lidarem com os efeitos do aquecimento global". ${ }^{17} \mathrm{Nas}$ Conferências climáticas subsequentes não houve indícios claros de que tipo de metas esses dois países assumiriam. A última Conferência do Clima, em Lima, 2014 (COP 20) teve como resultado o documento "Chamamento de Lima para a Ação sobre o Clima”, no qual se reconhece novamente o princípio das responsabilidades comuns, porém diferenciadas, e estabelece que todos os países devem submeter as suas metas voluntárias de redução das emissões ao longo do ano de 2015, deixando para a Conferência de Paris, ao final de 2015, as decisões mais importantes. ${ }^{18}$ Com relação às conferências realizadas no âmbito da ONU, 
não se avançou substancialmente na definição de metas e prazos, o que responde aos interesses da China em manter-se na posição de país em desenvolvimento e com metas voluntárias apenas. Mas também responde aos interesses dos Estados Unidos de adiar o máximo possível a adoção de metas ousadas, enquanto a China não fizer o mesmo.

Notícias recentes mostraram, no entanto, que os dois países deram passos importantes, mas que só valerão a partir de 2020 para os Estados Unidos e 2030 para a China, rumo a um quadro que englobe ações de mitigação destes dois maiores emissores de GEE do mundo, quando, em acordo bilateral, tanto Estados Unidos quanto China estipularam metas voluntárias de redução das emissões de GEE e de investimentos em energia limpa. ${ }^{19}$

\section{Considerações finais}

Como foi exposto, a China é um ator global no processo decisório da ordem ambiental internacional das mudanças climáticas. Maior emissor de GEE, é um protagonista fundamental nas relações econômicas atuais, além de ocupar posição de destaque no Conselho de Segurança da ONU, como membro permanente, e possuir um arsenal militar respeitável, incluindo armas nucleares.

A política interna chinesa baseia-se no desenvolvimento do país por meio da diminuição da pobreza, que ainda é expressiva. No contexto mundial contemporâneo, o país tornou-se fornecedor de produtos industrializados a grande parte dos países, o que levou a um crescimento muito significativo da sua economia, que foi realizado por meio de um intenso uso de carvão. As emissões chinesas cresceram para abastecer o mundo de produtos industrializados, mas também permitiram melhorias de qualidade de vida para parte de sua população. Por isso a posição chinesa na ordem ambiental internacional das mudanças climáticas é de cautela. Articulada ao G77, a China argumenta que suas emissões são menores se comparadas às emissões per capita de países industrializados. Por isso defende que as emissões sejam reduzidas primeiramente por eles.

Durante as negociações das duas Conferências das Partes analisadas neste artigo (Copenhague 2009, e Doha 2012), a China agiu em nome do G77 e em defesa de seus próprios interesses, tentando garantir que os resultados dessas negociações não prejudiquem o seu desenvolvimento econômico. O governo chinês mostra um alto nível de interesse na ordem ambiental internacional das mudanças climáticas, sendo parte ativa das rodadas de negociação da Convenção do Clima para a elaboração de um acordo climático futuro que envolva todos os países, mas não abdica das responsabilidades comuns, porém diferenciadas, como seu princípio fundador se recusando a admitir metas compulsórias de redução das emissões para os países em desenvolvimento, garantindo firmemente que a China ainda é um país em desenvolvimento.

Domesticamente, a China adotou o modelo da economia de baixo-carbono para enfrentar o desafio das mudanças climáticas e reduzir seus impactos na economia doméstica, enquanto mantém os objetivos do desenvolvimento eco- 
nômico e da redução da pobreza. Porém, a concentração de poder em poucas instituições e a ausência da sociedade civil podem retardar a implementação de ações mais concretas rapidamente.

$\mathrm{Na}$ arena internacional, a China participa das negociações sobre as mudanças climáticas e busca fortalecer a cooperação com outros países para financiamento, transferência de tecnologia e construção de capacidade para a adaptação. Por vezes atua em conjunto com países por meio do G77 ou do Basic para reforçar valores centrais de sua política externa para o clima. Como o atual número um em emissões absolutas de GEE, o país enfrentará uma crescente pressão global para aceitar obrigações internacionais visando as ações de mitigação das mudanças climáticas e deverá, portanto, ser cada vez mais difícil se ater ao princípio CBDR. Entretanto, ao assumir tais compromissos, a China pode colocar em risco o seu crescimento econômico sustentável, conforme afirma em termos domésticos. Essa decisão deve ser essencial para determinar o papel futuro da China não só na ordem ambiental internacional das mudanças climáticas, mas também como uma potência global em ascensão.

\section{Notas}

l Ordem ambiental do clima é o conjunto de instituições, documentos, acordos e regras que dispõem sobre a regulação da ação humana sobre o clima (Ribeiro, 2005). Ela é um subsistema da ordem ambiental internacional, definida por Ribeiro (2005) como uma forma de gestão coletiva da situação de crise ambiental em que vivemos atualmente, voltada à formulação de normas de conduta para regular a ação humana no ambiente em nível internacional.

2 Gamba e Ribeiro (23) fazem uma boa análise sobre a estrutura e realização da Conferência de Doha.

3 Essa participação foi possível graças aos recursos financeiros da reserva técnica de bolsa de doutorado da Fundação de Amparo à Pesquisa do Estado de São Paulo (Fapesp).

4 O IPCC, sigla para Intergovernmental Panel on Climate Change, é um painel criado em 1988 pela Organização Meteorológica Mundial e pelo Programa das Nações Unidas para o Meio Ambiente que reúne cientistas do mundo inteiro para organizar e publicar evidências científicas sobre as mudanças climáticas, de forma a fornecer embasamento técnico-científico para as negociações internacionais sobre o tema.

5 O G77 é um grupo formado por 77 países em desenvolvimento em 1964, quando estes assinaram a Declaração Conjunta dos Setenta e Sete Países com o objetivo de oferecer os meios pelos quais os países do Sul possam se articular e promover seus interesses econômicos coletivos e melhorar sua capacidade de negociação nos temas de maior interessa do sistema ONU. Informações disponíveis em: <http://www.g77. org/doc/index.html>. Acesso em: 27 nov. 2013.

$6 \mathrm{O}$ MDL é um mecanismo do Protocolo de Kyoto que permite a cooperação entre as Partes Anexo I e as Partes Não Anexo I da Convenção do Clima para a realização de projetos que resultem em diminuição das emissões de gases de efeito estufa. Para uma interpretação de sua implementação ver Souza e Ribeiro (2009). 
7 Dados retirados da página oficial da CQNUMC para o MDL. Disponível em: <http:// cdm.unfccc.int/Statistics/Registration/NumOfRegisteredProjByHostPartiesPieChart.html>. Acesso em: 16 out. 2012.

8 Entrevista com a Profa. Dra. Miranda Schreurs em 23 jul. 2013, em Berlim, durante estágio de pesquisa no exterior. Apoio financeiro da Fapesp.

9 O NCG é uma instituição do governo chinês para coordenar vários ministérios que atuam com a questão climática. Ele é responsável pela discussão dos principais assuntos envolvidos na área de mudanças climáticas, pela coordenação setorial em política e atividades climáticas, pela organização de negociações, e pela tomada de decisão nos temas intersetoriais relacionados às mudanças climáticas (Qi; Ma; Zhang, 2007, p.3).

10 Dados do Banco Mundial mostravam que, em 2011, 6,3\% da população chinesa vivia com menos de US\$ 1,25 por dia, e que, em 2013, o PIB per capita da China era de 6.560 dólares. Isso mostra que os planos quinquenais têm garantido um rápido crescimento econômico no país e tirado grande parte de sua população da linha de miséria. Dados disponíveis em: <http://povertydata.worldbank.org/poverty/country/ $\mathrm{CHN}>$. Acesso em: $16 \mathrm{dez} .2014$.

11 De acordo com a página oficial do Governo Chinês, o Plano Quinquenal “tem como objetivo providenciar projetos-chave de construção, gerenciar a distribuição das forças produtivas e as contribuições de setores individuais para a economia nacional, mapear a direção do desenvolvimento futuro, e estabelecer metas" (tradução livre). Disponível em: <http://english.gov.cn/2006-04/05/content_245556.htm>. Acesso em: 29 nov. 2013.

12 Documento disponível em: <http://unfccc.int/resource/docs/2011/awglcal4/ eng/inf01.pdf>. Acesso em: 15 out. 2012.

13 Artigo 4, parágrafo 7 da CQNUMC refere-se à condicionalidade da efetividade dos compromissos assumidos pelos países em desenvolvimento para a implementação efetiva dos compromissos assumidos pelos países desenvolvidos, no que se refere aos recursos financeiros e transferência de tecnologia.

14 Artigo 12, parágrafo 1 (b) refere-se à obrigação das Partes comunicarem ao Secretariado a descrição geral das ações tomadas, e o parágrafo 4 refere-se à natureza voluntária das propostas das Partes Não Anexo I.

15 Finalmente, o artigo 10, parágrafo 2(a) refere-se ao exame das informações comunicadas pelas Partes (Brasil, 2004).

16Documentodisponívelem:<http://en.ndrc.gov.cn/newsrelease/t20090521_280382. htm>. Acesso em: 27 nov. 2013.

17 Informações disponíveis em: <http://www.guardian.co.uk/environment/2012/ $\mathrm{dec} / 12 /$ china-us-global-climate-deal>. Acesso em: 21 mar. 2013.

18 Ver notícia disponível em <http://oglobo.globo.com/sociedade/sustentabilidade/conferencia-no-peru-termina-com-consenso-sobre-corte-de-emissoes-de-carbono-14830054>. Acesso em: 15 jan. 2015.

19 Ver notícia disponível em <http://gl.globo.com/natureza/noticia/2014/11/eua-e-china-anunciam-acordo-para-reduzir-emissao-de-gases-poluentes.html>. Acesso em: 16 dez. 2014. 
Referências

BAILEY, I. Copenhagen and the new political geographies of climate change. Political Geography, n.29, p.127-129, 2010.

BJØRKUM, I. China in the international politics of climate change: a foreign policy analysis. FNI Report 12/2005. The Fridtjof Nansen Institute, 2005. 82p.

BRASIL. Senado Federal. Subsecretaria de Edições Técnicas. Protocolo de Quioto e legislação correlata. Brasília, 2004. v.3 (Coleção Ambiental). 88p.

BRUNNÉE, J. From Bali to Copenhagen: towards a shared vision for a post-2012 climate regime?. Maryland Journal of International Law, v.25, n.86, p.86-108, 2010.

BUSTELO, P. China and Climate Change: responsible action? ARI 68/2007 (Translated from Spanish) - 31.7.2007 Disponível em: <http://www.realinstitutoelcano. org/wps/portal/rielcano_eng/Print?WCM_GLOBAL_CONTEXT=/wps/wcm/ connect/elcano/Elcano_in/Zonas_in/ARI\%2068-2007>. Acesso em: 26 nov. 2013.

GAMBA, C.; RIBEIRO, W. C. A encruzilhada brasileira na ordem ambiental internacional das mudanças climáticas. Estudos Avançados, v.27, n.78, 2013.

HEGGELUND, G.; ANDRESEN, S.; BUAN, I. F. Chinese Climate Policy: domestic priorities, foreign policy, and emerging implementation. In: HARRISON, K.; SUNDSTROM, L. M. (Ed.) Global Commons, Domestic decisions: the comparative politics of climate change. Massachusetts: The MIT Press, 2010. p.229-259.

HUNG, M.; TSAI, T.-C. Dilemma of choice: China's response to climate change. Revista Brasileira de Politica Internacional, v.55 (special edition), p.104-24, 2012.

LEWIS, J. I. Energy and Climate Goals of China's 12 ${ }^{\text {th }}$ Five-Year Plan. Pew Center on Global Climate Change. March 2011. Disponível em: <http://www.c2es.org/international/key-country-policies/china/energy-climate-goals-twelfth-five-year-plan>. Acesso em: 29 nov. 2013.

MARCOVITCH, J. Para mudar o futuro: mudanças climáticas, políticas públicas e estratégias empresariais. São Paulo: Edusp; Saraiva, 2006..

NDRC. National Development and Reform Commission of the People's Republic of China. China's National Climate Change Programme. Beijing: National Development and Reform Comission, 2007.

National Development and Reform Commission of the People's Republic of China. China's Position on the Copenhagen Climate Change Conference. Implementation of the Bali Road Map. Beijing: National Development and Reform Comission, 2009.

NIU, H. A grande estratégia chinesa e os BRICS. Contexto Internacional, v.35, n.1, p.197-229, jan./jul. 2013. Disponível em: <http://contextointernacional.iri.puc-rio. br/media/7artigo35l.pdf>. Acesso em: 16 dez. 2014.

OLIVEIRA, H. A. A crise asiática e a China. In: SEMINÁRIO DISSONÂNCIAS SINO-JAPONESAS DIANTE DA CRISE FINANCEIRA ASIÁTICA. São Paulo: Instituto de Estudos Avançados da Universidade de São Paulo, set. 1999.

QI, Y.; MA, L.; ZHANG, L. Climate change governance in China: a case study. China Population, Resources and Environment, v.17, n.2, March 2007.

RIBEIRO, W. C. A ordem ambiental internacional. 2.ed. São Paulo: Contexto, 2005. 
SERRA, S. B. A incógnita de Copenhagen. In: IV CONFERÊNCIA NACIONAL DE POLÍTICA EXTERNA E POLÍTICA INTERNACIONAL - IV CNPEPI. Seminário sobre Mudanças Climáticas. Rio de Janeiro, 19 de novembro de 2009. Brasília: Fundação Alexandre de Gusmão, 2010.

SOUZA, G. D.; RIBEIRO, W. C. NovaGerar: experiência pioneira do Brasil no MDL. Cronos, v.10, p.15-34, 2009.

THOMAS, G.; STEWART T. B. At the Energy Crossroads: Policies for a Low Carbon Economy. London: Fabian Society, 2001.

UNFCCC. United Nations Framework Convention on Climate Change. Copenhagen Accord. Geneva: Conference of the Parties, Fifteenth session, Draft decision -/CP.15, 2009. Availability: <http://unfccc.int/resource/docs/2009/copl5/eng/107.pdf>, Acesso em: 24 out. 2012.

United Nations Framework Convention on Climate Change. Compilation of information on nationally appropriate mitigation actions to be implemented by Parties not included in Annex I to the Convention. Geneva: Ad Hoc Working Group on Long-term Cooperative Action under the Convention, 2011. Disponível em: <http://unfccc.int/resource/docs/2011/awglcal4/eng/inf01.pdf>. Acesso em: 24 out. 2012.

. United Nations Framework Convention on Climate Change. Statement by China on behalf of Brazil, India, South Africa and China at COP 18. Doha, 2012. Disponível em: <http://unfccc.int/resource/docs/copl8_cmp8_hl_statements/ BASIC\%20STATEMENT\%20AT\%20COP18.pdf>. Acesso em: 30 nov. 2013.

VIOLA, E. As Complexas negociações internacionais para atenuar as mudanças climáticas. In: TRIGUEIRO, A. (Org.) Meio ambiente no século 21: 21 especialistas falam da questão ambiental nas suas áreas de conhecimento. 2.ed. Rio de Janeiro: Sextante, 2003. p.183-97.

RESUMO - As mudanças climáticas são consideradas um dos grandes desafios globais do século XXI. A China, como ator global e principal emissor de gases de efeito estufa, é um país-chave na política climática internacional. Sua posição é fundamental para o desenho do acordo futuro que substituirá o Protocolo de Kyoto e que regulará a ação humana sobre o sistema climático terrestre, dando continuidade ao conjunto de decisões internacionais que formam a ordem ambiental internacional das mudanças climáticas. Atendo-se à defesa do princípio das "responsabilidades comuns, porém diferenciadas", a China vem construindo seu posicionamento como um dos protagonistas dessa ordem desde o seu início, com a assinatura da Convenção do Clima em 1992. Este artigo parte do argumento de que a postura chinesa nas negociações internacionais sobre mudanças climáticas, apesar de muito participativa e fundamental para o encaminhamento das decisões globais sobre o tema, é definida em termos do interesse desenvolvimentista do Estado chinês. Durante as negociações das Conferências analisadas, a China agiu como liderança do G77 e em defesa dos seus próprios interesses, buscando garantir as responsabilidades diferenciadas e a classificação da China como país em desenvolvimento, evitando comprometer seus objetivos domésticos de desenvolvimento econômico. A última Conferência do Clima, em Lima, 2014, manteve o princípio das responsabilidades diferenciadas reforçando o interesse chinês, ainda que tenha estabelecido que todos os países apresentem metas voluntárias de redução das emissões. 
PALAVRAS-CHAVE: China, Mudanças climáticas, Ordem ambiental internacional, Desenvolvimento econômico.

ABSTRACT - Climate change is considered one of the greatest global challenges in the $21^{\text {st }}$ century. China, as a giant player in terms of territory, population and absolute emission of greenhouse gases, is a key country in international climate politics. Its position is fundamental for the design of the future agreement that will replace the Kyoto Protocol and regulate human action on Earth's climate system, ensuring the continuity of the international decisions that build the climate change environmental order. Advocating the principle of "common but differentiated responsibilities," China has established its position as one of the leading players of this new order since the beginning, with the signature of the Climate Change Convention in 1992. This article starts from the argument that China's position in international climate change negotiations, although very participative and fundamental to the global decisions on the issue, is defined in terms of developmental interest of the Chinese State. During the negotiations of these conferences, China acted as a leader of the Group of 77 and in defense of its own interests, trying to guarantee its differentiated responsibilities and its classification as a developing country, avoiding to compromise its domestic interests of economic development. The last Climate Change Conference, in Lima, in 2014, maintained the principle of differentiated responsibility, reinforcing the Chinese national interest, even though it established that each country should present its own voluntary emission reduction goals.

KErWORDS: China, Climate change, International environmental order, Economic development.

Helena Margarido Moreira é doutoranda em Geografia Humana na Faculdade de Filosofia, Letras e Ciências Humanas da USP. Bolsista Fapesp.

@ - helenamargarido@gmail.com

Wagner Costa Ribeiro é professor titular do Departamento de Geografia da Faculdade de Filosofia, Letras e Ciências Humanas da USP. Pesquisador CNPq. @ - wribeiro@usp.br Recebido em 15.1.2015 e aceito em 24.4.2015.

I, II Faculdade de Filosofia, Letras e Ciências Humanas, Universidade de São Paulo, São Paulo/São Paulo, Brasil. 
